\title{
COMPARISON OF THE TEST VARIANTS IN ENTRANCE EXAMINATIONS
}

Jindřich Klůfa

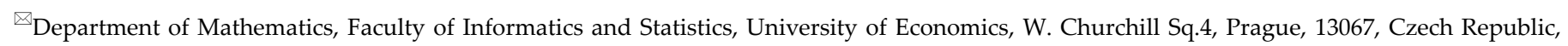
+420 224094 244, klufa@vse.cz

\section{Highlight}

- $\quad$ Dependence of the test results on the test variants

\begin{abstract}
The paper contains an analysis of the differences of number of points in the test in mathematics between test variants, which were used in the entrance examinations at the Faculty of Business Administration at University of Economics in Prague in 2015. The differences may arise due to the varying difficulty of variants for students, but also because of the different level of knowledge of students who write these variants. This problem we shall study in present paper. The aim of this paper is to study dependence of the results of entrance examinations in mathematics on test variants. The results obtained will be used for further improvement of the admission process at University of Economics.
\end{abstract}

\section{Keywords}

Entrance examinations, test variants, mathematics, statistical methods
Article type

Full research paper

Article history

Received: September 19, 2016

Received in revised form: November 21, 2016

Accepted: November 28, 2016

Available on-line: December 15, 2016

Kliffa J. (2016) "Comparison of the Test Variants in Entrance Examinations", Journal on Efficiency and Responsibility in Education and Science, Vol. 9, No. 4, pp. 111-116, online ISSN 1803-1617, printed ISSN 2336-2375, doi: 10.7160/eriesj.2016.090404.

\section{Introduction}

Students of the Faculty of Business Administration are accepted to study on the basis of tests in mathematics and language tests. The math tests are prepared by the Department of Mathematics of the Faculty of Informatics and Statistics. These tests are the multiple choice question tests (Klůfa, 2012), (Zhao, 2006), (Klůfa, 2013), (Premadasa, 1993), (Klůfa, 2015b). Multiple choice question tests are suitable for entrance examinations at university. These tests are objective, results can be evaluated easily for large number of students. On the other hand, a student can obtain certain number of points in the test purely by guessing the right answers. This problem is addressed in education research Premadasa (1993), Zhao (2005, 2006) - the probabilistic analysis shows that the optimum number of choices of answers for the multiple choice question tests is four, and for a four-choice question test, increasing from 8 questions to 18 and 48 questions reduces the probability of obtaining a good result by pure guesswork from about $5 \%$ to below $1 \%$ and $0.01 \%$, respectively. In Klůfa (2012) it was shown that risk of success of students with lower performance levels in entrance exams at

University of Economics in Prague is negligible (approximately one student in million successfully makes the entrance exams by pure guessing the answers), i.e. the multiple choice question tests are optimal for admission process. The multiple choice question tests from probability point of view with similar results are also in Klůfa (2013).

The tests in mathematics at the Faculty of Business Administration at University of Economics in Prague have 10 questions for 5 points and 5 questions for 10 points, i.e. 100 points total. Questions are independent. Each question has 5 answers, one answer is correct, wrong answer is not penalized. The number of points in the test in mathematics can be: 0 , $5,10,15,20,25,30,35,40,45, \ldots, 90,95,100$. Test variants in mathematics are generated from a database created by the Department of Mathematics. Test variants, which were used in the entrance examinations at the Faculty of Business Administration at University of Economics in Prague in 2015 we can find in Klůfa and Langhamrová (2015), part of one of these variants is in Figure 2 in Appendix. The database of the Department of Mathematics is divided into more of the groups, e.g. goniometric equations, sequences etc. From the selected groups is generated a question. Finally, the generated variants are chosen which are used for entrance examinations. The effort is to choose variants, which are equally difficult for students.

The aim of this paper is to analyse the differences of number of points in the test in mathematics between test variants, which were used in the entrance examinations at the Faculty of Business Administration in 2015. Similar problems are solved in Brožová and Rydval (2013), Hrubý (2013), Kaspříková (2012), Mošna (2013), Klůfa (2015c), Kubanová and Linda (2012), Coufal and Tobíšek (2015), Otavová and Sýkorová (2014). The dependence of study results and results of the entrance exams in mathematics is solved in Kubanová and Linda (2012). Analogous problem (the dependence of study results in mathematics on ways of acceptance students at university) is analysed in Klůfa (2015c). From results of these papers follows that students should be accepted to study on the basis of own admission process. University study results as related to the admission exam results we can find also in Kučera, Svatošová and Pelikán (2015). Analysis of the study results in basic courses in mathematics at University of Economics is in Kaspříková (2012) and Otavová and Sýkorová (2014). There is studied whether the score from final test depends on the score from mid-term test. Obtained results show that dependence between the score from final test and the score from mid-term test exists. The exam results in mathematics at Czech University of Life Sciences in Prague from the last 13 years have been analysed in Brožová and Rydval (2013). The reasons of low grades of students are discussed in this paper. Mathematics is generally said to be one of the unpopular school subjects. Popularization 
of mathematics (e-learning) is described in Coufal and Tobíšek (2015). E-learning and teaching of mathematics is also in Mošna (2013).

The differences between test variants may arise due to the varying difficulty of variants, but also because of the different level of knowledge of students who write these variants. This problem we shall study in present paper. The results obtained will be used to further improve of the preparation of test variants in coming years.

This paper is an extended version of the paper Klůfa (2016) results of other group of students, obtained in project "Entrance exams practice" in 2016, was analyzed.

\section{Material and Methods}

The analysed data are the results of the entrance examinations of 1514 students in mathematics at the Faculty of Business Administration in 2015. Six test variants, denoted A0, A8, A9, B0, B4, B6, were used for the entrance examinations in mathematics at the Faculty of Business Administration in 2015, other test variants were not used at this faculty. Differences between genders are not analysed in present paper.

On the other hand, the Department of Mathematics organizes preparatory courses for entrance examinations in mathematics. The results of one randomly selected parallel class (17 students) of these courses in 2016 will be analysed in this paper as well.

Furthermore, other results of 58 students, which were obtained in project "Entrance exams practice" in 2016, will be analysed in present paper.

For study the differences of number of points in the test in mathematics between 2 test variants we shall use paired t-test and t-test for independent samples. Statistic $t$ for paired test is

$$
t=\frac{\bar{d}}{s_{d}} \sqrt{n},
$$

where $d_{i}=x_{i}-y_{i}$, and $x_{i}, y_{i}$ is number of points in the test in mathematics of a student $i$ in 1st and 2nd test variant, $\bar{d}$ is average of values $d_{i}, s_{d}$ is standard deviation, $n$ is sample size ( 17 ). When

$$
|t|>t_{\alpha}(n-1)
$$

where $t_{\alpha}(n-1)$ is critical value of student $\mathrm{t}$ distribution with $(n-1)$ degrees of freedom, the hypothesis "mean number of points in 2 test variants is the same" is rejected at significance level $\alpha$.

Statistic $t$ for t-test for independent samples (under the same variance of samples) is

$$
t=\frac{\bar{x}-\bar{y}}{s \sqrt{\frac{1}{n_{1}}+\frac{1}{n_{2}}}}
$$

where $\bar{x}, \bar{y}$ is average number of points in the test in mathematics in 1 st and 2nd sample, $n_{1}, n_{2}$ is sample size in 1st and 2nd sample (in our case is $\left.n_{1}=n_{2}=29\right)$ and $s$ is standard deviation $\left(s_{x}, s_{y}\right.$ is standard deviations in 1 st and 2 nd sample) given by relation

$$
s=\sqrt{\frac{1}{n_{1}+n_{2}-2}\left[\left(n_{1}-1\right) s_{x}{ }^{2}+\left(n_{2}-1\right) s_{y}{ }^{2}\right.} .
$$

When

$$
|t| t_{\alpha}\left(n_{1}+n_{2}-2\right)
$$

where $t_{\alpha}\left(n_{1}+n_{2}-2\right)$ is critical value of student $t$ distribution with $\left(n_{1}+n_{2}-2\right)$ degrees of freedom, the hypothesis "mean number of points in 2 test variants is the same" is rejected at significance level $\alpha$.

For comparison of 6 test variants at the Faculty of Business Administration in 2015 we shall use ANOVA and Scheffé's method. We shall verify the validity of the null hypothesis: mean number of points in test variants A0, A8, A9, B0, B4, B6 is the same. When the test statistic (Rao, 1973)

$$
F>F_{\alpha}(k-1, n-k),
$$

where $F_{\alpha}(k-1, n-k)$ is critical value of Fischer-Snedecor distribution with $(k-1)$ and $(n-k)$ degrees of freedom, the hypothesis is rejected at significance level $\alpha$. In our case is $k=6$ (number of variants) and $n=1514$ (sample size for ANOVA).

\section{Results \\ Differences between the test variants}

The results of the entrance examinations of 1514 students in mathematics at the Faculty of Business Administration in 2015 are in Table 8, Table 9, Table 10, Table 11, Table 12, Table 13 in Appendix. Now we shall compare distributions of number of points in the test in mathematics in test variants $\mathrm{A} 0, \mathrm{~A} 8, \mathrm{~A} 9, \mathrm{~B} 0$, B4, B6 - see Figure 1 and Table 1.

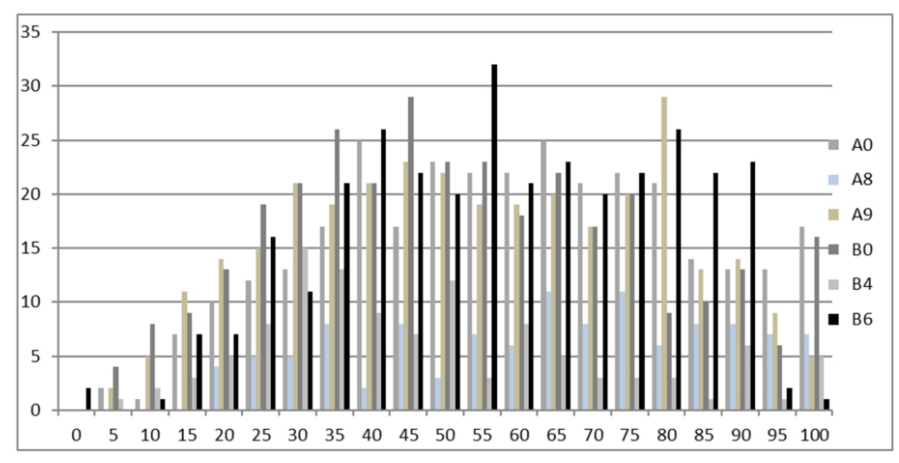

Figure 1: Distribution of number of points in test in mathematics in 2015 - test variants A0, A8, A9, B0, B4, B6 (histogram) (source: own calculation)

\begin{tabular}{|c|c|c|c|}
\hline $\begin{array}{c}\text { Test } \\
\text { variant }\end{array}$ & $\begin{array}{c}\text { Frequency } \\
\mathrm{n}_{\mathrm{i}}\end{array}$ & $\begin{array}{c}\text { Average number } \\
\text { of points }\end{array}$ & Variance \\
\hline $\mathrm{A} 0$ & 317 & 59.23 & 543.94 \\
\hline $\mathrm{A} 8$ & 114 & 64.17 & 540.23 \\
\hline $\mathrm{A} 9$ & 318 & 54.61 & 559.70 \\
\hline B0 & 327 & 52.54 & 584.03 \\
\hline B4 & 113 & 47.92 & 544.97 \\
\hline B6 & 325 & 57.31 & 462.71 \\
\hline
\end{tabular}

Table 1: Distribution of number of points in test - test variants A0, A8, A9, B0, B4, B6 (source: own calculation)

We shall test null hypothesis "the differences between average number of points in test variants A0, A8, A9, B0, B4, B6 in Table 1 are not statistically significant". 
To verify the validity of the hypothesis we use ANOVA. In the first step we verify assumption of this method by Bartlett's test, i.e. we verify the hypothesis "variance of number of points in test variants A0, A8, A9, B0, B4, B6 is the same". Test statistic $B$ (see e.g. Anděl (1978)) is $B=4.9$. Critical value of $\chi^{2}$ distribution for 5 degrees of freedom and significance level $\alpha=0.05$ is $\chi_{0.05}^{2}(5)=11.1$. Since $B<11.1$, the hypothesis "variance of number of points in test variants A0, A8, A9, B0, B4, B6 is the same" is not rejected at 5\% significance level, assumption of ANOVA can be considered to have been met.

\begin{tabular}{|l|c|c|c|c|c|c|}
\hline $\begin{array}{l}\text { Source of } \\
\text { variability }\end{array}$ & $\begin{array}{c}\text { Sum of } \\
\text { Squares }\end{array}$ & $\begin{array}{c}\text { Degrees of } \\
\text { freedom }\end{array}$ & Fraction & F & p value & F crit \\
\hline $\begin{array}{l}\text { Test } \\
\text { variants }\end{array}$ & 23365.02 & 5 & 4673.00 & 8.68 & $\begin{array}{c}3.99 \mathrm{E}- \\
08\end{array}$ & 2.22 \\
\hline Residual & 811706.13 & 1508 & 538.27 & & & \\
\hline Sum & 835071.15 & 1513 & & & & \\
\hline
\end{tabular}

Table 2: Results of ANOVA (source: own calculation)

Results of ANOVA we got with MS Excel (Marek, 2013) - see Table 2. Since

$$
F=8.68>2.22
$$

the null hypothesis is rejected at 5\% significance level. There are some differences between the test variants, the differences between average number of points in test variants $\mathrm{A} 0, \mathrm{~A} 8, \mathrm{~A} 9$, B0, B4, B6 in Table 1 are statistically significant.

Finally we shall study which pairs of averages differ significantly. We use Scheffé's method (Anděl, 1978). Pairs of averages differ significantly if absolute value of difference in averages exceeds critical value

$$
\sqrt{\left(\frac{1}{n_{i}}+\frac{1}{n_{j}}\right) \times 5 \times 538.27 \times 2.22}
$$

where 538.27 is the residual variance and 2.22 is the critical value from Table 2 .

\begin{tabular}{|c|c|c|c|c|c|c|}
\hline $\begin{array}{c}\text { Test } \\
\text { variant }\end{array}$ & A0 & A8 & A9 & B0 & B4 & B6 \\
\hline A0 & & 4.94 & 4.62 & 6.69 & $11.31^{*}$ & 1.92 \\
\hline A8 & & & $9.56^{*}$ & $11.63^{*}$ & $16.25^{*}$ & 6.86 \\
\hline A9 & & & & 2.07 & 6.69 & 2.70 \\
\hline B0 & & & & & 4.62 & 4.77 \\
\hline B4 & & & & & & $9.39^{*}$ \\
\hline B6 & & & & & & \\
\hline
\end{tabular}

*Significant difference for $\alpha=0.05$ (Scheffé's method)

Table 3: Absolute value of differences between average number of points in test variants $\mathrm{A0}, \mathrm{A8}, \mathrm{A9}, \mathrm{B0}, \mathrm{B} 4, \mathrm{B6}$ (source: own calculation)

From Table 3 it is seen that a significant difference is at 5\% significant level between $\mathrm{A} 0$ and $\mathrm{B} 4, \mathrm{~A} 8$ and $\mathrm{A} 9, \mathrm{~A} 8$ and $\mathrm{B} 0$, A8 and B4, B4 and B6. All other pairs of averages are not significantly different. Greatest significant difference is between the test variants $\mathrm{A} 8$ and $\mathrm{B} 4$.

\section{Difference between A8 and B4 - paired t test}

Significant differences between test variants may arise due to the varying difficulty of variants for students, but also because of the different level of knowledge of students who write these variants. Therefore we shall now study results of the same group of students - see results of 17 students in preparatory course for entrance examinations in 2016 in Table 4.

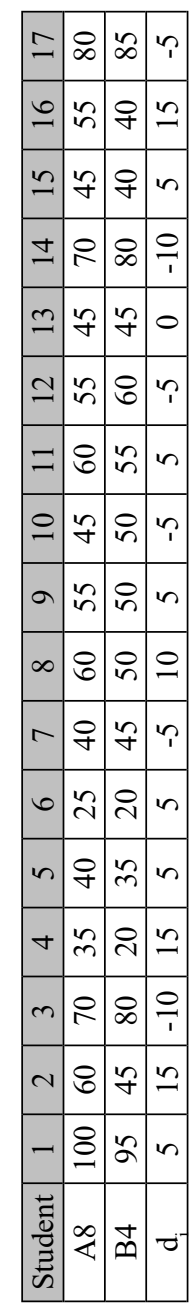

Table 4: Number of points in mathematics in test variants $\mathrm{A8}$ and B4 (source: own calculation)

From Table 4 we have average number of points in mathematics in test variants A8 $\bar{x}_{A 8}=55.29$ and average number of points in mathematics in test variants B4 $\bar{x}_{B 4}=52.65$.

Now we shall test null hypothesis "the difference between these average number of points in test variants $\mathrm{A} 8, \mathrm{~B} 4$ is not statistically significant".

We have two results for the same student. It means that the samples in Table 4 are not independent. Therefore, to verify the validity of the hypothesis we use paired t test. According to (1) we have

$$
t=1.31
$$

Critical value of $t$ distribution for 16 degrees of freedom and significance level $\alpha=0.05$ is $t_{0.05}(16)=2.12$. Since

$$
|t|<2.12
$$

the null hypothesis is not rejected at 5\% significance level. Because $t_{0.20}(16)=1.34$, this hypothesis is not rejected also at $20 \%$ significance level. The difference between average number of points in test variants A8 and B4 in preparatory course for entrance examinations in 2016 is not statistically significant.

\section{Difference between A8 and B4 - t test for independent samples}

Now we shall compare other results of 58 students, which were obtained in project "Entrance exams practice" in 2016 
(two different groups of students, each group has 29 students, i.e. $n_{1}=n_{2}=29$ ). These students wrote test variants $\mathrm{A} 8$ and B4 once more, results are in Table 14 in Appendix, descriptive statistics for distributions of number of points in the test in mathematics in test variants A8 and B4 are in Table 5.

\begin{tabular}{|c|c|c|}
\hline Test variant & A8 & B4 \\
\hline Average number of points & 47.931 & 40.517 \\
\hline Median & 45 & 30 \\
\hline Modus & 15 & 25 \\
\hline Variance & 588.42 & 572.04 \\
\hline Kurtosis & -0.854 & -0.616 \\
\hline Skewness & 0.181 & 0.714 \\
\hline
\end{tabular}

Table 5: Descriptive statistics for number of points in mathematics in test variants $\mathrm{A8}$ and $\mathrm{B} 4$ (source: own calculation)

From Table 5 we have average number of points in mathematics in test variants A8 $\bar{x}_{A 8}=47.93$ and average number of points in mathematics in test variants B4 $\bar{x}_{B 4}=40.52$.

Now we shall test null hypothesis "the difference between these average number of points in test variants A8, B4 is not statistically significant".

We have results of two different groups of students, i.e. the results are independent. Therefore, to verify the validity of the hypothesis we use t-test for independent samples. In the first step we verify assumption of the same variance of samples by Fisher-Snedecor F-test. The hypothesis "variance of number of points in test variants A8 and B4 is the same" is not rejected at $5 \%$ significance level ( $p$-value is 0.47 ), assumption of the t-test for independent samples can be considered to have been met.

Results of the t-test for independent samples we got with MS Excel (Marek, 2013) - see Table 6. According to (3) we have

$$
t=1.172
$$

Critical value of $t$ distribution for 56 degrees of freedom and significance level $\alpha=0.05$ is $t_{0.05}(56)=2.003$. Since

$$
|t|<2.003
$$

the null hypothesis is not rejected at 5\% significance level. Because p-value is 0.246 (see Table 6), this hypothesis is not rejected also at $24 \%$ significance level. The difference between average number of points in test variants A8 and B4 in project "Entrance exams practice" in 2016 is not statistically significant.

\begin{tabular}{|c|c|c|}
\hline Alfa $=0.05$ & A8 & B4 \\
\hline Average & 47.931 & 40.517 \\
\hline Variance & 588.42 & 572.04 \\
\hline Sample size & 29 & 29 \\
\hline Standard deviation (see (4)) & 24.088 & \\
\hline Degrees of freedom & 56 & \\
\hline t Stat & 1.172 & \\
\hline p- value & 0.246 & \\
\hline Critical value & 2.003 & \\
\hline
\end{tabular}

Table 6: Results of the t-test for independent samples (source: own calculation)

\section{Discussion}

From results of this paper it follows that the difference between average number of points in mathematics in test variants $A 8$ and B4 in entrance exams in 2015 is statistical significant - see also second row of Table 7 . Therefore, we ask whether these test variants are equally difficult for students.

\begin{tabular}{|c|c|c|}
\hline Test variant & A8 & B4 \\
\hline $\begin{array}{c}\text { 2 different groups of students in } \\
\text { entrance exams in 2015 }\end{array}$ & $\bar{x}_{A 8}=64.17$ & $\bar{x}_{B 4}=47.92$ \\
\hline $\begin{array}{c}\text { 1 group of students in preparatory } \\
\text { course in 2016 }\end{array}$ & $\bar{x}_{A 8}=55.29$ & $\bar{x}_{B 4}=52.65$ \\
\hline $\begin{array}{c}2 \text { different groups of students in } \\
\text { project "Entrance exams practice" } \\
\text { in 2016 }\end{array}$ & $\bar{x}_{A 8}=47.93$ & $\bar{x}_{B 4}=40.52$ \\
\hline
\end{tabular}

Table 7: Average number of points in mathematics (source: own calculation)

For the same group of students in preparatory course in 2016 the difference between average number of points in mathematics in test variants $\mathrm{A} 8$ and $\mathrm{B} 4$ is not statistical significant - see also third row of Table 7. For two different groups of students in project "Entrance exams practice" in 2016 the difference between average number of points in mathematics in test variants A8 and B4 is not statistical significant, either. It means that the difference between test variants A8 and B4 in entrance exams in 2015 could be caused by other factors, e. g. by the different level of knowledge of students who wrote these variants in entrance exams in 2015.

Entrance exams in mathematics at the University of Defence in Brno with similar problems are analysed in Hošková-Majerová and Račková (2010) - examples in mathematics with the same level of difficulty. Analysis of the entrance examination in mathematics at University of Pardubice we can find in Linda and Kubanová (2013) - correlation between results of the entrance examination test in mathematics and examination in mathematics at the university. The aim of these papers was a little different. Analysis of the entrance tests in mathematics at Faculty of mathematics, physics and informatics at Comenius University in Bratislava we can find in Kohanová (2012). The focus of the paper is to find what types of tasks should be included in the entrance test if we want to select students who have best predispositions for study. Similar statistical methods here were used as in present paper.

The problem of the same difficulty of tests variants in entrance examination, which is mentioned in this paper, occurs in scientific papers only rarely. One of them is paper written by Klůfa (2015a). There is on the basis of test of independence in contingency table shown that results of entrance examinations at the Faculty of Informatics and Statistics at University of Economics in Prague do not depend on the test variants, i.e. the analogous result as in present paper.

\section{Conclusion}

The differences between average number of points in mathematics in test variants $\mathrm{A} 0, \mathrm{~A} 8, \mathrm{~A} 9, \mathrm{~B} 0, \mathrm{~B} 4, \mathrm{~B} 6$, which were used for the entrance examinations in mathematics at the Faculty of Business Administration in 2015, are statistically significant. The differences may arise due to the varying difficulty of variants, but also because of the different level of knowledge of students who write these variants. From results of this paper it follows that these significant differences between tests variants may arise due to different level of knowledge of 
the students who wrote these variants. On the other hand, the difficulty of test variants for students is poorly measured. This problem will be solved in the following paper.

Significant changes in test variants in mathematics in the coming years are not needed. But increase the homogeneity test variants would be very useful. Therefore the database created by the Department of Mathematics will be further modified - the database will be expanded and divided into more of the groups.

\section{Acknowledgements}

This paper was processed with contribution of long term institutional support of research activities by Faculty of Informatics and Statistics, University of Economics, Prague.

\section{References}

Anděl, J. (1978) Matematická statistika. Praha: SNTL/ALFA. Brožová, H., Rydval, J. (2013) ‘Analysis of the exam test quality’, Efficiency and Responsibility in Education, Proceedings of the 10th International Conference, Prague, pp. 47-54.

Coufal, J., Tobíšek, J. (2015) 'Mathematics and e-learning', The 9th International Days of Statistics and Economics, Prague, pp.270-278.

Hošková-Majerová, Š, Račková, P. (2010) 'Problematic examples at the entrance exams of mathematics at the University of Defence', Procedia - Social and Behavioral Sciences, vol. 9, pp. 348-352. http://dx.doi.org/10.1016/j.sbspro.2010.12.162

Hrubý, M. (2013) 'Extended elements of the question objects', Efficiency and Responsibility in Education, Proceedings of the 10th International Conference, Prague, pp. 204-209.

Kaspříková, N. (2012) 'Data analysis of students' performance', Efficiency and Responsibility in Education, Proceedings of the 9th International Conference, Prague, pp. 213-218.

Klůfa, J. (2012) 'Tests from probability point of view', Efficiency and Responsibility in Education, Proceedings of the 9th International Conference, Prague, pp. 229-233.

Klůfa, J. (2013) 'Comparison of entrance examinations in mathematics', Efficiency and Responsibility in Education, Proceedings of the 10th International Conference, Prague, pp. 270-275.

Klůfa, J. (2015a) 'Dependence of the Results of Entrance Examinations on Test Variants', Procedia - Social and Behavioral Sciences, vol. 174, pp. 3565-3571. http://dx.doi. org/10.1016/j.sbspro.2015.01.1073

Klůfa, J. (2015b) 'Analysis of entrance examinations', Efficiency and Responsibility in Education, Proceedings of the 12th International Conference, Prague, pp. 250-256.

Klůfa, J. (2015c) 'Comparison of the Ways of Acceptance Students at University', Journal on Efficiency and Responsibility in Education and Science, vol. 8, no. 3, pp. 72-76. http://dx.doi. org/10.7160/eriesj.2015.080204

Klůfa, J., Langhamrová, J. (2015) Matematika - připrava $k$ prijímacím zkouškám na VŠE, Prague: Ekopress.

Klůfa, J. (2016) 'Analysis of the differences between results of test variants', Efficiency and Responsibility in Education, Proceedings of the 13th International Conference, Prague, pp. 279-285.

Kohanová, I. (2012) 'Analysis of university entrance test from mathematics', Acta Didactica Universitatis Comenianae Mathematics, vol. 12, pp.31-46.

Kučera, P., Svatošová, L., Pelikán, M. (2015) 'University study results as related to the admission exam results' Efficiency and Responsibility in Education, Proceedings of the 12th International Conference, Prague, pp. 318-324.
Kubanová, J., Linda, B. (2012) 'Relation between results of the learning potential tests and study results', Journal on Efficiency and Responsibility in Education and Science, vol. 5, no 3, pp.125-134. http://dx.doi.org/10.7160/eriesj.2012.050302

Linda, B., Kubanová, J. (2013) 'Relation between results of the entrance examination test in mathematics and examination in mathematics at the university', Efficiency and Responsibility in Education, Proceedings of the 10th International Conference, Prague, pp. 370-373.

Marek, L. (2013) Statistika v príkladech, Prague: Professional Publishing.

Mošna, F. (2013) 'E-learning and interactive dynamical figures for teaching of mathematics', Efficiency and Responsibility in Education, Proceedings of the 10th International Conference, Prague, pp. 449-454.

Otavová, M., Sýkorová, I. (2014) 'Analysis of Scores from Mid-Term and Final Test by a Contingency Table', Efficiency and Responsibility in Education, Proceedings of the 11th International Conference, Prague, pp. 527-533.

Premadasa, I. (1993) 'A reappraisal of the use of multiple-choice questions', Medical Teacher, vol. 15, no. 2-3, pp. 237-242.

Rao, C.R. (1973) Linear Statistical Inference and Its Applications, New York: John Wiley.

Zhao, Y. (2005) 'Algorithms for converting raw scores of multiple-choice question tests to conventional percentage marks', International Journal of Engineering Education, vol. 21, no. 6, pp. 1189-1194.

Zhao, Y. (2006) 'How to design and interpret a multiple-choicequestion test: A probabilistic approach', International Journal of Engineering Education, vol. 22, no. 6, pp. 1281-1286. 


\section{Appendix}

Number of points in test in mathematics in 2015 - test variant A0 606520756025756525590702060601008540951006030 30905090703540757060553055757020603555608565 6070505520501001580358085356530602580701005550 550804050554060759540753025553580808045455535 7035854020756510045855075552070555045100652565 75551535307045354575259565804550954015404055 654035201007080203590705545452525458010010075 60907045658540751580555580707590206590554565 556565602565302035855050601008080658035407575 50557590906085805065705035603050454550954540 30105055704060408030406035757040155540504025 45808540703055405515759045307040603515503050 403560705075607585656585657525659510090956585 852510010080701001009560904085959565651005090 80707595100959540655080

Table 8: Results of the entrance examinations in mathematics at the Faculty of Business Administration in 2015 (source: own data)

Number of points in test in mathematics in 2015 - test variant A8 70959575454565502590902060557535404545556075 853020508070654565758555656560857010070556050 358075757070405530805510025353585306565753535 65607580804510075202590906590100854520253535 304590853075609565805525709575959570909585100 100100659085

Table 9: Results of the entrance examinations in mathematics at the Faculty of Business Administration in 2015 (source: own data)

Number of points in test in mathematics in $\mathbf{2 0 1 5}$ - test variant A9 85203050754525652570506585208080353515259545 35802045656540404535703065352580504085407510 45502065706045405045652570703075756530407580 40454570103040407090459515808080653055805535 55504070253095957075751510406090353020905550 55502035857010307065603090353565515401556075 10455515503020707540752080302520154060503590 50453590907525503075604560808080409040502550 70258560206035255050856535802540854045707055 95606580653035202555404555954585355555453530 75505060407020208045455035556060156555153025 60203060305030804045158060558090455085758075 75603030157580808055757580806580808090456525 856090459580357090555010075100956590100558565 6510055906095551008585

Table 10: Results of the entrance examinations in mathematics at the Faculty of Business Administration in 2015 (source: own data)

Number of points in test in mathematics in $\mathbf{2 0 1 5}$ - test variant B0 40559040359515106545506590555020654525153050 75503045704525305010901040656055202560603520 100153510020304035357554025608590451565405025 303535456560454565560654555803065304540758515 65954595454035807515955075404030358075159050 30556565353580252065554525705351002075601040 35353070459060359070753510070751008030354570 40656510754060304020559075603025355020554075 507565451570356585905055351002555105545302535 70309015602075954070807565655570455070556545 35255510255090502560506550258555554575452545 352035402060205060355025306570585104555456030 45405560452530705530254040854050502075555570 604555551007010050951009035851003085100508575 100801001007045801008030507510090857560257045

Table 11: Results of the entrance examinations in mathematics at the Faculty of Business Administration in 2015 (source: own data)
Number of points in test in mathematics in 2015 - test variant B4 30303080602540404545306050606530152050407030 3065354055254025304030252030904052545603535 453525303520501002050405030553530351050804020 15655070603525554560153565507060451075455030 352530353590905060758010085509010050100959090 356510075

Table 12: Results of the entrance examinations in mathematics at the Faculty of Business Administration in 2015 (source: own data)

Number of points in test in mathematics in $\mathbf{2 0 1 5}$ - test variant B6 80455570856050654530905070702545556090858535 40656070651003555307565040356520554020508065 35804580658085853080654560553550255520603545 15707025255575504075409080504075758075359055 40807565901590906050303025806540303075355035 457560557002065706030356575902535303550254050 60254575457585604570358560404070253585605080 90505540207040405540356570758060406555903560 55506515405050554530604575555540854555553540 25103560557570755025553080458020402570256580 45557585559085509040701555756580655545405520 45856040705565808050456535551565407580402555 85907045605565701540758095505590258560458590 50856045859085908525758080759060809090458535 95908015559070808565708055903585

Table 13: Results of the entrance examinations in mathematics at the Faculty of Business Administration in 2015 (source: own data)

\begin{tabular}{|c|c|}
\hline $\begin{array}{c}\text { Test } \\
\text { variant }\end{array}$ & Number of points in test in mathematics in $\mathbf{2 0 1 6}$ \\
\hline A8 & 1570654520203010085408045152050556015 \\
8045707045506015654020 \\
\hline B4 & $\begin{array}{c}5052525354045302575702525153015305590 \\
75408525802010353065\end{array}$ \\
\hline
\end{tabular}

Table 14: Results obtained in project "Entrance exams practice" in 2016 (source: own data)

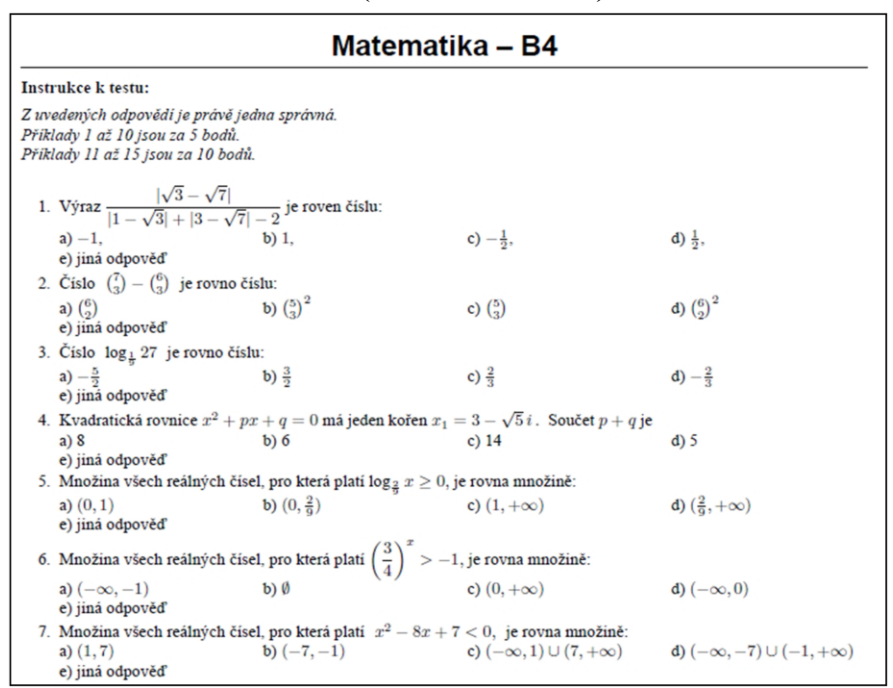

Figure 2: Part of the test variant B4 in mathematics in 2015 (source: own construction) 